\title{
Von Willebrand Disease, Type 2N
}

National Cancer Institute

\section{Source}

National Cancer Institute. von Willebrand Disease, Type 2N. NCI Thesaurus. Code C131689.

An autosomally inherited (generally recessive) coagulation disorder characterized by qualitative abnormalities of the von Willebrand factor (VWF). The mutant VWF shows markedly decreased binding affinity for factor VIII, which can be confused with mild hemophilia A. The phenotype is characterized by a disproportionate decrease in factor VIII compared to VWF. 